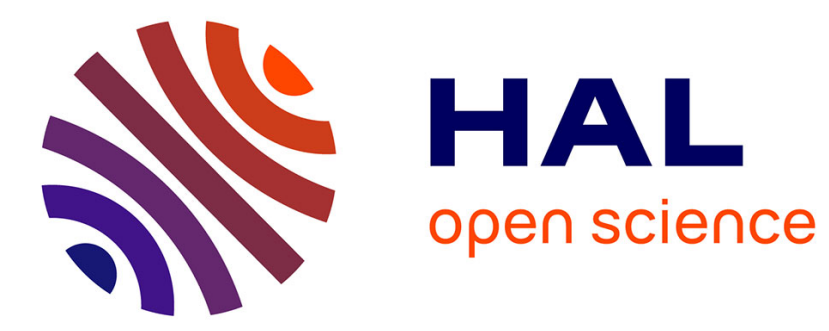

\title{
Characteristics of the Warming Trend During Winter Wheat Growing Seasons in Jiangsu Province of China
}

\author{
Xiangying Xu, Xinkai Zhu, Wenshan Guo, Chunyan Li, Jinfeng Ding
}

\section{To cite this version:}

Xiangying Xu, Xinkai Zhu, Wenshan Guo, Chunyan Li, Jinfeng Ding. Characteristics of the Warming Trend During Winter Wheat Growing Seasons in Jiangsu Province of China. 11th International Conference on Computer and Computing Technologies in Agriculture (CCTA), Aug 2017, Jilin, China. pp.127-138, 10.1007/978-3-030-06179-1_14. hal-02111536

\section{HAL Id: hal-02111536 \\ https://hal.inria.fr/hal-02111536}

Submitted on 26 Apr 2019

HAL is a multi-disciplinary open access archive for the deposit and dissemination of scientific research documents, whether they are published or not. The documents may come from teaching and research institutions in France or abroad, or from public or private research centers.
L'archive ouverte pluridisciplinaire HAL, est destinée au dépôt et à la diffusion de documents scientifiques de niveau recherche, publiés ou non, émanant des établissements d'enseignement et de recherche français ou étrangers, des laboratoires publics ou privés. 


\title{
Characteristics of the warming trend during winter wheat growing seasons in Jiangsu Province of China
}

\author{
Xiangying $\mathrm{Xu}^{1,2}$, Xinkai Zhu ${ }^{1}$, Wenshan Guo ${ }^{1,(凶),}$ Chunyan $\mathrm{Li}^{1}$, Jinfeng Ding ${ }^{1}$ \\ ${ }^{1}$ Jiangsu Provincial Key Lab of Crop Genetics and Physiology/Wheat Research Institute, \\ Yangzhou University, Yangzhou, China \\ ${ }^{2}$ Information and engineering college of Yangzhou University, Yangzhou, China
}

\begin{abstract}
Global warming has great influences on crop yields. However, several researchers have concluded that global warming has taken a "hiatus" in recent years. Here, we hope to identify the temperature trends of the winter wheat growing seasons and quantitatively estimate the effects of temperature variations on wheat yields. We carry out trend analysis on daily maximum (Tmax) and minimum temperatures (Tmin) from 1980 to 2014 in Jiangsu Province of China. The results indicate there are increasing trends for both Tmax and Tmin during 35 years, but no significant trends in the years after 2000. In addition, the increasing rates of the Tmin are larger than those of Tmax over the 35 years within all stations and all growing stages, which suggests that winter wheat is exposed to asymmetrical warming. The results of correlation analysis and regression analysis reveal that increases in Tmin have significant adverse effects on wheat yields.
\end{abstract}

Key words: winter wheat; yield; asymmetric warming;

\section{Introduction}

Global warming has received much attention in public and scientific fields. Researchers have found increases in average temperatures of the land surface, and that the minimum (mostly nighttime) temperatures, Tmin, and the maximum (mostly daytime) temperatures, Tmax, have increased asymmetrically during the past decades [1,2]. As firstly reported by Karl et al. (1984), asymmetric warming, which means the rate at which Tmin increases is larger than the rate at which Tmax increases, has been confirmed in most parts of the world $[3,4,5]$. The reason for this may involve a variety of factors, such as changes in cloud cover and urban growth. However, as described in IPCC (the Intergovernmental Panel on Climate Change) Fifth Assessment Report, there has been a slowdown in the increasing trend of global temperatures since the end of the last century, which was termed as a "hiatus" [6]. Several recent modeling studies have shown that the reason for this anomaly may be related to a La Niña-like cooling, volcanic eruptions, or the strengthening Pacific trade winds over the past twenty years $[7,8,9,10]$. Nevertheless, some other studies do not agree with the point that a "hiatus" was appeared in the global warming trend $[11,12]$. They believe that short-term variations do not change the ongoing global warming.

Despite the different opinions about the global warming trend, most scholars generally share similar

\footnotetext{
$\triangle$ Corresponding author at: Jiangsu Provincial Key Lab of Crop Genetics and Physiology/Wheat Research Institute, Yangzhou University, Yangzhou 225009, China. Tel: +86 87979339. E-mail: guows@ yzu.edu.cn.
} 
views about the threat of increasing temperatures to crop production. Many studies have been carried out to reveal the impacts of global warming on crop production, especially the yield and quality formation, with simulated crop models and field experiments [13, 14, 15, 16, 17]. Scholars found that the global long-term warming trend had changed crop production, including shortened growing periods and shifting planting boundaries. However, most of the simulation models used in recent studies are less accurate at higher temperatures than normal ones [18]. Further, the field experiments with artificial heating have limitations in observing the long-term temperature trends and have difficulties detecting long-term crop responses to temperature. Therefore, in this study, we resorted to statistical methods and used observation data to investigate the effects of temperature on crop yields.

Jiangsu is a major province of agriculture in China, and it has a dense population. Winter wheat is a staple crop in Jiangsu. Wheat production has an important effect on the livelihood of the people and the provincial economy. However, the province is situated in a transition zone between warm temperate zones to subtropical zones. Extreme climatic events, including extreme temperatures, take place with high frequency in Jiangsu Province. Although the authors of several studies have shown that Jiangsu became warming obviously in the past decades [16, 25, 29], few of them reveal the warming trend of winter wheat growing seasons as well as the quantitative estimation of wheat yields variations in the warming circumstance. Therefore, in this study, the objectives are to analyze the temperature evolution of wheat growing seasons during the past 35 years in Jiangsu and quantify the wheat yield responses to temperatures to help farmers cope with future climatic changes and ensure there is a reliable food supply in this area.

\section{Materials and Methods}

\subsection{Data}

Daily temperature data from 1979 to 2014 of four meteorological stations in Jiangsu Province was obtained from the China Meteorological Administration [19]. To analyze the temperature evolution of winter wheat growing seasons, we divided the whole growing season into four stages according to the periods mentioned in the main crop growth period database of the National Agricultural Scientific Data Sharing Center [20]. The four stages are: seedling stage (S1), overwintering stage (S2), reviving to anthesis stage (S3), post-anthesis stage (S4). The locations and wheat growing seasons of the four stations are shown in Table 1. The yearly yields per hectare of the four stations during $1980-2014$ were obtained from the local statistical yearbooks.

Table 1. Locations and growing seasons of four meteorological stations in Jiangsu Province

\begin{tabular}{|c|c|c|c|c|c|c|}
\hline Stations & Latitude & Longitude & S1 & S2 & S3 & S4 \\
\hline Ganyu & $34^{\circ} 30^{\prime} \mathrm{N}$ & $119^{\circ} 04^{\prime} \mathrm{E}$ & \multirow{2}{*}{$\begin{array}{l}15^{\text {th }} \text { Oct. } \\
\sim 25^{\text {th }} \text { Dec. }\end{array}$} & \multirow{2}{*}{$\begin{array}{l}26^{\text {th }} \text { Dec. } \\
\sim 25^{\text {th }} \text { Feb. }\end{array}$} & \multirow{2}{*}{$\begin{array}{l}26^{\text {th }} \text { Feb. } \\
\sim 25^{\text {th }} \text { Api. }\end{array}$} & \multirow{2}{*}{$\begin{array}{l}26^{\text {th }} \text { Api. } \\
\sim 2^{\text {nd }} \text { Jun. }\end{array}$} \\
\hline Xuzhou & $34^{\circ} 10^{\prime} \mathrm{N}$ & $117^{\circ} 05^{\prime} \mathrm{E}$ & & & & \\
\hline Dongtai & $32^{\circ} 31^{\prime} \mathrm{N}$ & $120^{\circ} 11^{\prime} \mathrm{E}$ & \multirow{2}{*}{$\begin{array}{l}25^{\text {th }} \text { Oct. } \\
\sim 5^{\text {th }} \text { Jan. }\end{array}$} & \multirow{2}{*}{$\begin{array}{l}6^{\text {th }} \text { Jan. } \\
\sim 20^{\text {th }} \text { Feb. }\end{array}$} & \multirow{2}{*}{$\begin{array}{l}21^{\text {th }} \text { Feb. } \\
\sim 20^{\text {th }} \text { Api. }\end{array}$} & \multirow{2}{*}{$\begin{array}{l}21^{\text {th }} \text { Api. } \\
\sim 28^{\text {th }} \text { May }\end{array}$} \\
\hline Nanjing & $32^{\circ} 00^{\prime} \mathrm{N}$ & $118^{\circ} 29^{\prime} \mathrm{E}$ & & & & \\
\hline
\end{tabular}

\subsection{Mann-Kendall Test for Temperature Trend Analysis}

The nonparametric Mann-Kendall test was used in this study for the trend analysis of temperatures during winter wheat growing seasons. It is a rank-based testing method recommended by WMO (the World Meteorological Organization) and is widely used in meteorology, hydrology, and other fields 
[21]. Because temperature data does not always follow normal distribution, like most meteorological data, it is better to choose a nonparametric test method than a parameter test to avoid using the parameters of population distributions. The merit of this method is that the data need not to obey the normal distribution and it can eliminate the interference of a few outliers [22]. The calculation of MannKendall test is as follows:

Suppose $\mathrm{X}$ is a time series $\left(\mathrm{x}_{1}, \mathrm{x}_{2}, \mathrm{x}_{3} \ldots \mathrm{x}_{\mathrm{n}}\right)$. The original hypothesis $\left(\mathrm{H}_{0}\right)$ is that $\mathrm{X}$ has no significant changing trend, while the alternative hypothesis $\left(\mathrm{H}_{1}\right)$ assumes it has. Firstly, the $\mathrm{S}$ value is calculated thusly:

$$
\mathrm{S}=\sum_{k=1}^{n-1} \sum_{j=k+1}^{n} \operatorname{sgn}\left(x_{j}-x_{k}\right)
$$

where $\mathrm{x}_{\mathrm{j}}, \mathrm{x}_{\mathrm{k}}$ are the values in time series $\mathrm{X}(\mathrm{j}>\mathrm{k})$. The sgn is a sign function, which is calculated as follows:

$$
\operatorname{sgn}\left(x_{j}-x_{k}\right)=\left\{\begin{array}{c}
+1, x_{j}-x_{k}>0 \\
0, x_{j}-x_{k}=0 \\
-1, x_{j}-x_{k}<0
\end{array}\right.
$$

When the sample length (n) is larger than 10 , the statistical variable $S$ is supposed to be approximately normal and the expectation of $\mathrm{S}$ is 0 . The variance is calculated as follows:

$$
\operatorname{VAR}(\mathrm{S})=\frac{1}{18}\left[n(n-1)(2 n+5)-\sum_{i} e_{i}\left(e_{i}-1\right)\left(2 e_{i}+5\right)\right]
$$

where $e_{i}$ is the number of repeated variables. Then transform $\mathrm{S}$ to $\mathrm{Z}$, which follows the standardized normal distribution.

$$
\mathrm{Z}= \begin{cases}\frac{S-1}{\sqrt{\operatorname{VAR}(S)}}, & S>0 \\ 0, & S=0 \\ \frac{S+1}{\sqrt{\operatorname{VAR}(S)}}, & S<0\end{cases}
$$

When $|Z| \geq Z_{\alpha / 2}$, the alternative hypothesis is accepted at the $\alpha$ significant level. A positive $Z$ value indicates that sequence $X$ has an increasing trend, while a negative one indicates that $X$ has a decreasing trend. We use Sen's slope to compute the value of the trends following the method described in the paper of Santos M. et al. [23]. The formulation of the slope is as follows:

$$
\text { Slope }=\operatorname{median}\left(\left(\mathrm{x}_{\mathrm{j}}-\mathrm{x}_{\mathrm{k}}\right) /(\mathrm{j}-\mathrm{k})\right)
$$

where the notations of $x_{j}$ and $x_{k}$ are the same as equation (1). Function median is used to calculate the median.

\subsection{Yield De-Trending}

To evaluate the yield responses to the variability of temperature, we collected data about annual wheat yields for 35 years. Benefiting from the improvements in cultivation techniques and the optimization of government policies, the yields of the four sites consistently increased in past decades. To eliminate bias 
caused by technological improvements, the linear trend was removed from the original yield series, and the residuals of the yields were obtained as meteorological yields [24]. The statistical analysis of wheat yield responses to temperatures was performed using the de-trended yields of four stations. The distribution of the de-trended yields was fitted with the normal distribution and passed the KolmogorovSmirnov (K-S) test which was used to compute a distance between the empirical and cumulative distribution function of the de-trended yield sequences [24]. The null hypothesis is that the yield residuals sequence accord with the theory distribution of normal, and the result indicates that it cannot be rejected. The frequency histogram of yield residuals is shown in Fig. 1.

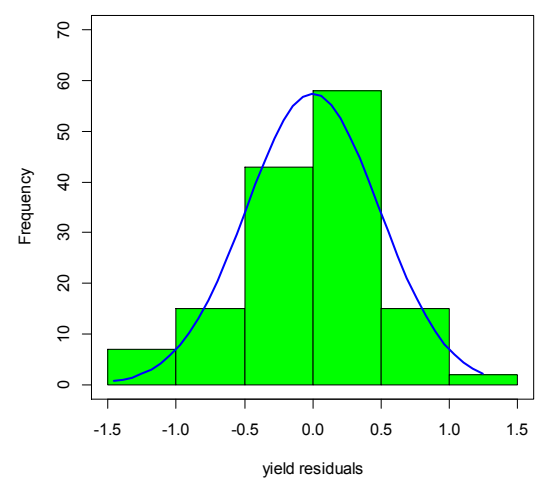

Fig. 1. Frequency histogram of yield residuals of four stations

\subsection{Correlation Analysis and Regression Analysis}

The Pearson coefficient was applied in this study to determine the correlation between wheat yields and growing season temperatures. The calculation was performed in R software, and the coefficient of the linear association is between -1 and +1 .

Multivariate regression was used to estimate the impacts of changes in Tmax and Tmin on wheat yields. The formula is as follows:

$$
\mathrm{Y}=\mathrm{const}+\alpha * \mathrm{Tmax}+\beta * \mathrm{Tmin}
$$

where $\mathrm{Y}$ is the yield residuals. $\alpha$ and $\beta$ are the coefficients of Tmax and Tmin.

\section{Results}

\subsection{Temperature Trend}

Temperature Trend of the Winter Wheat Growing Season. The air temperature data about the growing seasons at the four stations were computed. Trend analysis was used to detect the temperature trends from 1980 to 2014 compared to the trends in the years before and after 2000. Table 2 shows the annual changes in the Tmax, Tmin, and Tavg (average daily temperatures) values of the four stations during wheat growing seasons by Mann-Kendall test and Sen's slope method.

Table 2. Changes of annual average temperatures during wheat growing seasons

\begin{tabular}{lllll}
\hline \multirow{2}{*}{ Periods } & Stations & \multicolumn{3}{c}{ Trend slope $\left({ }^{\circ} \mathrm{C} /\right.$ year $)$} \\
\cline { 3 - 5 } & Ganyu & Tavg & Tmax & Tmin \\
\hline \multirow{2}{*}{$1980-2014$} & Xuzhou & $0.044^{* *}$ & $0.032^{*}$ & $0.057^{* *}$ \\
& Dongtai & $0.046^{* *}$ & $0.029^{*}$ & $0.061^{* *}$ \\
& Nanjing & $0.056^{* *}$ & $0.044^{* *}$ & $0.048^{* *}$ \\
& & & $0.050^{* *}$ & $0.071^{* *}$ \\
\hline
\end{tabular}




\begin{tabular}{lllll}
\hline & Ganyu & $0.075 * *$ & $0.074 * *$ & $0.116^{* *}$ \\
$1980-1999$ & Xuzhou & $0.048^{*}$ & 0.042 & $0.068^{* *}$ \\
& Dongtai & $0.077^{* *}$ & $0.076^{* *}$ & $0.090^{* *}$ \\
& Nanjing & $0.077 * *$ & $0.077^{* *}$ & $0.096^{* *}$ \\
\hline \multirow{2}{*}{$2000-2014$} & Ganyu & -0.075 & -0.022 & $-0.141^{*}$ \\
& Xuzhou & -0.003 & -0.003 & -0.014 \\
& Dongtai & -0.038 & -0.027 & -0.049 \\
& Nanjing & -0.010 & 0.004 & -0.017 \\
\hline
\end{tabular}

Note: Tavg, Tmax, and Tmin represent the average, maximum, and minimum temperatures of the day, respectively. **,* indicate trend significance at $P<0.01,0.05$.

The result indicates that from 1980 to 2014, the average, maximum, and minimum daily temperatures in wheat growing seasons significantly increased. Compared to the other three stations, the southern station, Nanjing, has the largest slope. However, the Tmin increased faster than the Tmax at all four stations. This result is similar to the conclusion drawn by Shaobing Peng et al. [26] in their study of rice yields at latitude $14^{\circ} 11 \mathrm{~N}$, longitude $121^{\circ} 15 \mathrm{E}$. When we divide the period of 35 years into two stages (the last 20 years and the first 15 years of the 20th and 21 st century), entirely different trends are revealed. In the years before 2000, the temperature significantly increased at most of the stations, and the Tmin increased faster than Tavg and Tmax. On the contrary, in the years after 2000, the variations of the temperatures are not significant in most stations and the signs of the slope are negative, indicating that the temperatures have downward trends. These anomalies in the winter wheat growing seasons are similar to the temperature anomalies mentioned as the "hiatus" in the global warming of this century in other studies. Nevertheless, whether the changes in the trends are short-term fluctuations is still unknown.

Temperature Trends of Four Growing Stages. Because temperature variations in different growing stages may lead to different effects on wheat yields, we analyzed the temperature trends in four stages. The results are shown in Table 3. Because the average temperature is between the maximum and minimum temperatures and it evolved similarly as them, it was not taken into consideration.

Table 3. Changes in the maximum and minimum temperatures during the four growing stages

\begin{tabular}{|c|c|c|c|c|c|c|}
\hline \multirow[t]{2}{*}{ Periods } & \multirow[t]{2}{*}{ Stations } & & \multicolumn{4}{|c|}{ Trend slope $\left({ }^{\circ} \mathrm{C} /\right.$ year $)$} \\
\hline & & & S1 & S2 & S3 & S4 \\
\hline \multirow[t]{8}{*}{$1980-2014$} & \multirow[t]{2}{*}{ Ganyu } & Tmax & 0.014 & 0.024 & $0.055^{*}$ & 0.046 \\
\hline & & Tmin & $0.049^{*}$ & 0.048 & $0.063^{* *}$ & $0.056^{* *}$ \\
\hline & \multirow[t]{2}{*}{ Xuzhou } & Tmax & 0.010 & 0.029 & $0.055^{*}$ & 0.025 \\
\hline & & Tmin & $0.047 * *$ & $0.057^{* *}$ & $0.077^{* *}$ & $0.066^{* *}$ \\
\hline & \multirow[t]{2}{*}{ Dongtai } & Tmax & 0.018 & 0.033 & $0.096^{* *}$ & $0.055^{*}$ \\
\hline & & Tmin & $0.039^{*}$ & 0.037 & $0.060^{* *}$ & $0.052 * *$ \\
\hline & \multirow[t]{2}{*}{ Nanjing } & Tmax & 0.017 & 0.026 & $0.116^{* *}$ & $0.054 *$ \\
\hline & & Tmin & $0.082 * *$ & $0.066^{* *}$ & $0.083^{* *}$ & $0.068 * *$ \\
\hline \multirow[t]{7}{*}{ 1980-1999 } & \multirow[t]{2}{*}{ Ganyu } & Tmax & 0.058 & $0.126^{* *}$ & 0.022 & 0.028 \\
\hline & & Tmin & $0.116^{*}$ & $0.153^{* *}$ & $0.110^{* *}$ & $0.077^{*}$ \\
\hline & \multirow[t]{2}{*}{ Xuzhou } & Tmax & 0.046 & $0.114^{*}$ & -0.003 & -0.044 \\
\hline & & Tmin & 0.057 & $0.124^{* *}$ & $0.084 *$ & 0.031 \\
\hline & \multirow[t]{2}{*}{ Dongtai } & Tmax & 0.068 & $0.072^{* *}$ & $0.085^{*}$ & 0.040 \\
\hline & & Tmin & $0.092 *$ & $0.093^{*}$ & $0.086^{*}$ & $0.093 *$ \\
\hline & Nanjing & Tmax & 0.057 & $0.090^{*}$ & 0.075 & 0.015 \\
\hline
\end{tabular}




\begin{tabular}{|c|c|c|c|c|c|c|}
\hline & & Tmin & $0.089 *$ & $0.095^{*}$ & 0.087 & $0.081 * *$ \\
\hline \multirow[t]{8}{*}{$2000-2014$} & Ganyu & Tmax & -0.003 & -0.019 & -0.107 & 0.088 \\
\hline & & Tmin & -0.126 & -0.153 & $-0.176^{*}$ & -0.037 \\
\hline & Xuzhou & Tmax & 0.053 & -0.032 & -0.102 & 0.041 \\
\hline & & Tmin & -0.019 & -0.012 & -0.049 & 0.043 \\
\hline & Dongtai & Tmax & 0.022 & 0.001 & -0.037 & 0.060 \\
\hline & & Tmin & -0.086 & -0.060 & -0.060 & 0.034 \\
\hline & Nanjing & Tmax & 0.024 & -0.004 & -0.036 & 0.058 \\
\hline & & Tmin & 0.010 & -0.028 & -0.020 & 0.016 \\
\hline
\end{tabular}

Note: S1, S2, S3, and S4 represent seedling stage, overwintering stage, reviving and jointing stage, and post-anthesis stage, respectively. $* *, *$ indicate a significant trends at $P<0.01,0.05$, respectively.

Different trends were observed in the three study periods and four growing stages. From 1980 to 2014 , the temperatures in the reviving and jointing stages (S3) and post-anthesis stages (S4) significantly increased. Similarly, Tmin increased faster than Tmax in most cases, except at Dongtai and Nanjing during S3. Nevertheless, during the 20 years before 2000, temperatures of overwintering stages (S2) increased more pronouncedly than in other stages. Furthermore, during the 15 years after 2000, there are hardly any obvious trends in the four stages at all stations, except Ganyu in S3.

Fig. 2 illustrates the temperature trends over 35 years. It shows that during S3 and S4, Tmax and Tmin were generally higher in this century than in the last century, except for several low points in the trends, among which the most obvious one is the anomaly around 2010. In contrast, the peak values of the trends do not show obvious decreases compared to the temperatures in the years before 2000. This may confirm the hypothesis that global warming in the 21 st century is expected to resume once the anomalous hiatus ends [7].
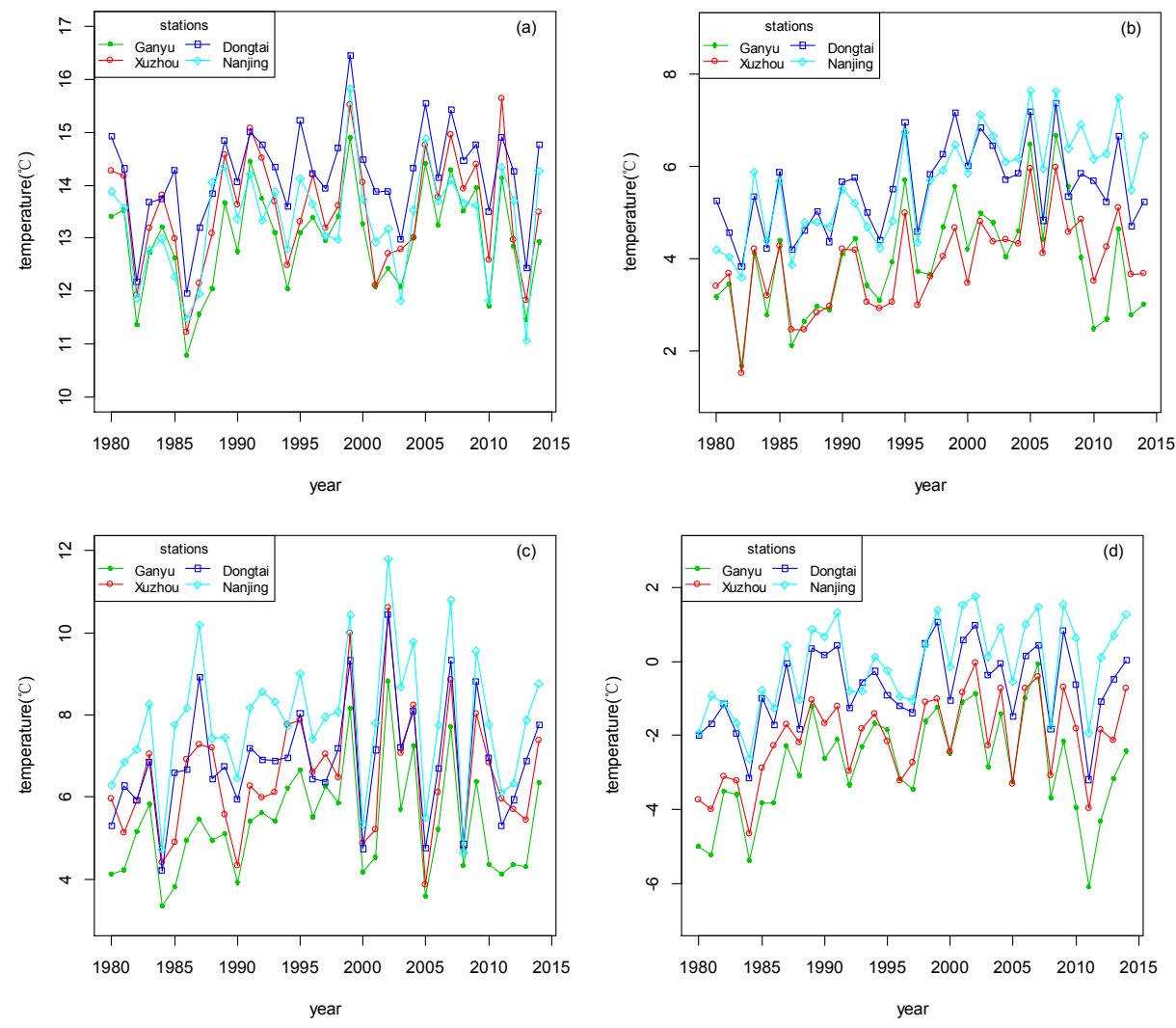

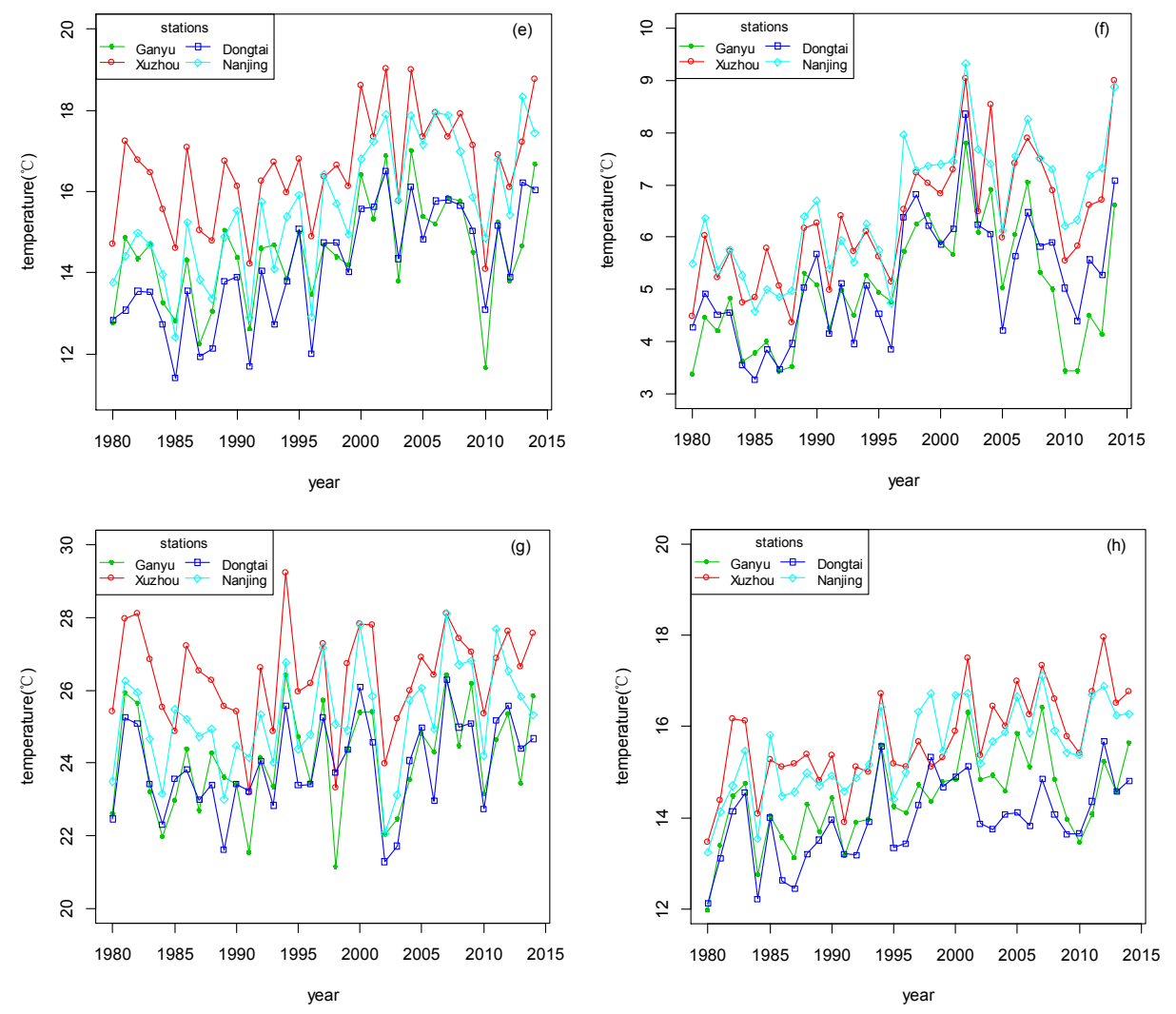

Fig. 2. The maximum and minimum temperatures in seedling stage (S1), overwintering stage (S2), reviving and jointing stage (S3), and post-anthesis stage (S4).

Note: (a), (c), (e), and (g) are the maximum temperatures of the four stations during S1, S2, S3, and S4, respectively. (b), (d), (f), and (h) are the minimum temperatures of the four stations during S1, S2, S3, and S4, respectively.

\subsection{Correlation between Yield and Temperature}

The correlation between winter wheat yield and temperature was analyzed by using the Pearson correlation coefficient and regression analysis. We used yield and temperature residuals to calculate the Pearson coefficients for all 35 years. The result indicates that average temperature of the whole growing season has a significantly negative influence on wheat yields $(\mathrm{r}=-0.24)$. Tmin has a very significant $(\mathrm{P}$ $<0.01)$ influence on wheat yields $(r=-0.30)$ while Tmax has a less pronounced correlation with wheat yields. In addition, the correlations between yield and Tmax and Tmin during the four growing stages have been computed (see Table 4). Besides S4, the Tmin values of the other three stages have significant negative relationships with wheat yields from the four stations.

Table 4. The Pearson correlation coefficients of wheat yields and temperatures over 35 years

\begin{tabular}{lll}
\hline Stage & Tmax & Tmin \\
\hline Whole growing season & -0.12 & $-0.30^{* * *}$ \\
S1 & -0.12 & $-0.20^{*}$ \\
S2 & -0.13 & $-0.28^{* *}$ \\
S3 & -0.18 & $-0.27^{* *}$ \\
S4 & $0.21^{*}$ & -0.09 \\
\hline
\end{tabular}

Note: S1, S2, S3, and S4 represent seedling stage, overwintering stage, reviving and jointing stage, and post-anthesis stage, respectively. $* * * * *$ and $*$ indicate correlation significance of $P<0.001,0.01$, and 0.05 , respectively. 


\subsection{Yield Responses to Temperature}

The regression model (Formula 7) shows that yield residuals are significantly affected by Tmin $(\mathrm{P}<0.001)$ but not significantly affected by Tmax. This result indicates that the increasing minimum temperatures of the wheat growing season have more adverse effects on the yield. A $0.1^{\circ} \mathrm{C}$ increase in minimum temperature will cause wheat yield losses of $28.5 \mathrm{~kg} / \mathrm{ha}$.

$$
\mathrm{Y}=0.091 * \mathrm{~T} \max -0.285 * \mathrm{Tmin}
$$

Table 5 reveals the quantitative yield responses to temperature of the four growing stages. We can conclude that the Tmin of each growing stage is significantly related to wheat yields and Tmin increases would lead to yield losses. Moreover, the Tmin in S4 has the biggest influence according to the coefficients. This may be due to the fact that the late growth stage of winter wheat is more important in yield formation. Interestingly, only in S4 was Tmax found to have a significant positive correlation with wheat yields. This implies that the effects of temperatures on wheat yields are unbalanced for day and night. Zhang et al. (1994) report that low night temperatures can significantly prolong the relative steady phase (RSP) of chlorophyll content and photosynthetic active duration (PAD) and, thereby, increase the leaf source capacity and wheat yields [27]. Zhang et al. (2012) also report that nocturnal warming significantly reduces soil microbial biomass carbon and nitrogen content and microbial respiration rate. Therefore, it affects soil nutrient supply and winter wheat growth [28]. For these reasons, the minimum temperatures, which have obviously increased in recent decades, deserve much attention due to their adverse effects. The Tmax of the post-anthesis stage, which does not increase as significantly as Tmin, has positive effects on wheat yield improvement because it promotes photosynthesis, increasing the enzyme activity of the crop and enlarging the diurnal temperature range (DTR) $[29,16]$. The results of the regression analysis suggest that the Tmax and Tmin of each growing stage account for only $2.8 \%$ to $9.3 \%$ of the yield variations. It appears that the asymmetric warming during the past 35 years did not seriously affect the wheat yields in Jiangsu Province. A similar conclusion was obtained by Hou et al. (2012) in the study of the North China Plain (NCP) [30].

Table 5. The regression analysis of wheat yield residuals

\begin{tabular}{lllll}
\hline Stage & & Tmax & Tmin & $\mathrm{R}^{2}$ \\
\hline \multirow{2}{*}{$\mathrm{W}$} & Coef. & 0.091 & $-0.285^{* * *}$ & 0.080 \\
& p-value & 0.310 & 0.0006 & 0.001 \\
\multirow{2}{*}{ S1 } & Coef. & -0.017 & $-0.105^{*}$ & 0.028 \\
& p-value & 0.715 & 0.047 & 0.051 \\
& Coef. & 0.031 & $-0.147^{* *}$ & 0.070 \\
S2 & p-value & 0.399 & 0.002 & 0.003 \\
& Coef. & 0.004 & $-0.144^{*}$ & 0.061 \\
S3 & p-value & 0.935 & 0.014 & 0.005 \\
& Coef. & $0.140^{* * *}$ & $-0.196^{* *}$ & 0.093 \\
S4 & p-value & 0.0002 & 0.003 & 0.0004 \\
\hline
\end{tabular}

Note: W, S1, S2, S3, and S4 represent the whole growing season, seedling stage, overwintering stage, reviving and jointing stage, and post-anthesis stage, respectively. Coef. represents coefficient. *, ** and *** indicate statistical significance of $P<0.05,0.01$, and 0.001 .

\section{Discussion and Conclusions}

Besides the impacts of temperature, winter wheat yields are influenced by many other meteorological factors, such as precipitation, solar radiation, and wind speed. However, a comparison of these other 
meteorological factors shows that temperature has the most obvious changing trend in Jiangsu, which may change precipitation frequency and intensity according to the results of studies on other areas in Asia [31]. Therefore, temperature variations have considerable influences on wheat production.

In this study, the Tmax and Tmin changes in the winter wheat growing seasons display a significantly asymmetrical warming trend in Jiangsu Province. The increasing rate of Tmin is obviously larger than that of Tmax over the 35 years examined in this study. We cannot confirm the existences of a global warming "hiatus" because there are no significant increasing or decreasing trends for both Tmax and Tmin during all growing stages of 2000-2014. The temperatures of the four growing stages display similar asymmetrical trends in Tmax and Tmin. Moreover, the Tmin values of the pre-anthesis stages have negative influences on wheat yields, while the Tmax values of the post-anthesis stages have positive influences on wheat yields. The regression model indicates that Tmin has had more adverse influences on wheat yields than Tmax, regardless of growth stage, during the past 35 years. Generally, according to our study, the impacts of temperature increase on wheat yields over the past three decades are not serious. This result partly reflects the adaptability of crop production in Jiangsu Province.

The present research is conducted on four stations. The next step of our research is to collect observations from a dense grid of stations in Jiangsu and obtain accurate results that cover the whole province.

Acknowledgments. This work was supported by the National Key Research and Development Program of China (2016YFD0300107) and the Specialized Research Fund for the Doctoral Program of Higher Education (doctoral supervisor) (NO: 20133250110001). It was also supported by the National Natural Science Foundation of China (NO: 31401317).

\section{References}

1. Karl T. R., George Kuk, et al. Global warming: Evidence for asymmetric diurnal temperature change. Geophysical Research Letters, , DECEMBER 1991,VOL.18,NO.12,Pages 2253-2256.

2.Karl T. R., Jones P. D., Knight R. W., et al. A new perspective on recent global warming: Asymmetric trends of daily maximum and minimum temperature[J]. Bulletin of the American Meteorological Society, 1993, 74(6):1007 -1023 .

3.Easterling D. R., Horton B., Jones P. D., et al. Maximum and minimum temperature trends for the globe[J]. Science, 1997, 277(18): 364-367.

4..Shushi Peng1, Shilong Piao1, et al. Asymmetric effects of daytime and night-time warming on Northern Hemisphere vegetation. Nature, 2013, Vol.501:88-95

5. Md. Abu Zafer Siddik, Mursheda Rahman.Trend analysis of maximum, minimum, and average temperatures in Bangladesh: 1961-2008. Theoretical and Applied Climatology, May 2014, Volume 116, Issue 3-4, pp 721-730.

6. T. F. Stocker, D. Qin, G.-K. Plattner, M. Tignor, S.K. Allen, et al. IPCC, Climate Change 2013: The Physical Science Basis. Contribution of Working Group I to the Fifth Assessment Report of the Intergovernmental Panel on Climate Change. Cambridge University Press, Cambridge, United Kingdom and New York, NY, USA, 2013.

7. Matthew H. England, Shayne McGregor, et al. Recent intensification of wind-driven circulation in the Pacific and the ongoing warming hiatus. Nature Climate Change. 2014. 4 (3) :222-227.

8. Yu. Kosaka, S.-P. Xie, Recent global-warming hiatus tied to equatorial Pacific surface cooling. Nature 501, 403-407 (2013). Medline doi:10.1038/nature12534 
9. B. D. Santer, C. Bonfils, J. F. Painter, M. D. Zelinka, C. Mears, S. Solomon, G. A.Schmidt, J. C. Fyfe, J. N. S.

Cole, L. Nazarenko, K. E. Taylor, F. J. Wentz, Volcanic contribution to decadal changes in tropospheric temperature. Nat. Geosci. 7,185-189 (2014). doi:10.1038/ngeo2098

10. David R. Easterling, Michael F. Wehner. Is the climate warming or cooling? Geophysical Research Letters , 2009 , 36 (8): 262-275

11. Niamh Cahill, Stefan Rahmstorf, Andrew C Parnell. Change points of global temperature. Environmental Research Letters , 2015,10 (8) :S309. doi:10.1088/1748-9326/10/8/084002

12. T.R. Karl, Anthony Arguez, Boyin Huang, et al.Possible artifacts of data biases in the recent global surface warming hiatus. Science, 2015, 348 (6242):1469

13. Sharon M Gourdji, Adam M Sibley, David B Lobell. Global crop exposure to critical high temperatures in the reproductive period: historical trends and future projections. Environmental Research Letters , 2013 , 8 (2) :024041. doi:10.1088/1748-9326/8/2/024041

14. Delphine Deryng, Declan Conway, et al. Global crop yield response to extreme heat stress under multiple climate change futures. Environmental Research Letters , 2014 , 9 (3) :2033-2053

15. David B Lobell,Claudia Tebaldi. Getting caught with our plants down: the risks of a global crop yield slowdown from climate trends in the next two decades. Environmental Research Letters, 2014,9 (7) :74003$74010(8)$

16. .Zhao Hui. Physiological effects of post-anthesis high temperature and water stress on wheat quality formation. Nanjign Agricultural University.2006.

17. Li Ke-nan, YANG Xiao-guang, et al. The Possible Effects of Global Warming on Cropping Systems in China VIII-The Effects of Climate Change on Planting Boundaries of Different Winte-Spring Varieties of Winter Wheat in China. Scientia Agricultura Sinica. 2013,46(8):1583-1594. doi: 10.3864/j.issn.0578-1752.2013.08.007

18. S. Asseng et al. Rising temperatures reduce global wheat production. Nature climate change. 22 DEC. 2014:143-147.DOI: 10.1038/NCLIMATE2470

19. National Meteorological Information Center of China Meteorological Administration, http://data.cma.cn/site/index.html

20. Main crop growth period database of the National Agricultural Scientific Data Sharing Center, http://old.agridata.cn/module_db/index_new.asp?Rid=A070413

21. Cao Jieping et al.Mann-Kendall Examination and Application in the Analysis of Precipitation Trend. Agricultural Science \& Technology and Equipment. No.5 Total No.179.Oct,2008. DOI: 10. 16313 /j.cnki.nykjyzb.2008.05.008

22. Khaled H. Hamed et al. Trend detection in hydrologic data: The Mann-Kendall trend test under the scaling hypothesis.Journal of Hydrology.Volume 349, Issues 3-4, 1 February 2008, Pages 350-363.

23. Santos M., Fragoso M. Precipitation variability in Northern Portugal: Data homogeneity assessment and trends in extreme precipitation indices. Atmospheric Research, 2013 , 131 (5) :34-45

24. Potopová V., Štěpánek P., Možný M., Türkott L., Soukup J. Performance of the standardized precipitation evapotranspiration index at various lags for agricultural drought risk assessment in the Czech Republic. Agricultural \& Forest Meteorology,2015,202(202):26-38

25. Zhou Xiaolan, Gao Qingjiu, et al. Long Term Temperature Trends and Spatial Patterns of the Inter-Decadal Variations in Jiangsu. Journal of Nanjing Institute of Meteorology. Vol. 29 No. 2, Apr. 2006.

26. Shaobing Peng, Jianliang Huang, et al. Rice yields decline with higher night temperature from global warming. Proceedings of the National Academy of Sciences of the United States of America, 2004,101 (27):9971

27. Zhang Rongxian, Fang Zhiwei. Influence of different nighttime temperatures on the photosynthesis of the flag leaf and yield in wheat. Acta Agronomica Sinica, Nov.1994,VOL.20.No.6:710-715.(in Chinese) 
28. Zhang Mingqian, Han Zhengfang, et al. Impact of nighttime warming on soil microbial biomass carbon/nitrogen and activity in main winter wheat cropping areas in China. Chinese Journal of Eco-Agriculture, Nov. 2012, 20(11): 1464-1470.(in Chinese)

29. Fan Yonghui. Effects of winter and spring night warming on grain yield formation in wheat and its phusiological mechanism. Nanjign Agricultural University.2015.

30. Hou Ruixing, Ouyang Zhu, et al. Is the change of winter wheat yield under warming caused by shortened reproductive period? Ecology and Evolution, 2012 , 2 (12) :2999-3008

31. Shobha Poudel, Rajib Shaw. The Relationships between Climate Variability and Crop Yield in a Mountainous Environment: A Case Study in Lamjung District, Nepal. Climate, 2016,4(1), 13.DOI:10.3390/cli4010013. 